\title{
Electronprobe Microanalysis of Volcanic Glass at Cryogenic Temperatures
}

\author{
S.L.Kearns*, N.Steen*, and E.Erlund*
}

*Department of Earth Sciences, University of Bristol, Queens Road, Bristol, UK, BS8 1RJ

Analysis of volcanic glass is of particular importance to volcanologists and petrologists, due to the fact that fresh, unaltered volcanic glass provides the best evidence for the composition and initial conditions of the magma from which it formed. However, for many volcanic systems, the production of good quantitative analyses is problemmatic due to the interstitial nature of the glass (fig1) and the instability of the sample under the impact of a high energy electron beam on the surface.

Previous studies have established that alkali ions, especially sodium and potassium migrate away from the point of beam impact during routine EPMA of glasses yielding erroneous results[1,2,3]. The mechanism of alkali transport has been the focus of several studies [4,5]. An initial study here has investigated the effects both at normal ambient temperatures (198K, fig 2$)$ and cryogenic temperatures $(83 \mathrm{~K}$, fig 3 ) by means of a liquid nitrogen cooled cryo-stage across a broad range of volcanic glass compositions. The glasses studied have between 48 and 76 wt \% $\mathrm{SiO}_{2}$ and varying concentrations of sodium and potassium and other non-volatile components. The water content of each glass was independently determined by FTIR spectroscopy. All analyses were performed on a Cameca Camebax Micro operating under SAMX automation software.

Under 'normal' wavelength dispersive EPMA operating conditions, a typical analysis might take between two and four minutes depending on the number of spectrometers available, the number of elements analysed and the required precision and detection limits for theelements concerned. Results (figs 2 and 3) show that there is a strong relationship between initial temperature and stability of the alkali species during the course of a single analysis.

Under cryogenic conditions the glass is seen to be immune to theheating effects of the electron beam and alkali ions will remain stable in the sample. Consequently it is possible to analyse these materials with higher beam currents, smaller spot sizes and longer dwell times than is possible under ambient temperature conditions. Analysis performed using the cryo-stage can yield a marked improvement in the precision and detection limits of both major and minor elements compared with normal operating conditions. This has important implications for the interpretation of vdcanic glass compositions. Many other mineral systems, e,g, feldspars, hydrous phyllosilicates, carbonates etc. may also benefit from analysis at cryogenic temperatures where samples prove to be unstable under the heating effects of the electron beam.

\section{References}

[1] Borom, M.P. and Hanneman, R.E. 1967 Jour. Applied Phys 38

[2] Morgan, G.B. and London, J. 1996 Am. Mineral. 81

[3] Neilsen, C.H. and Sigurdsson, H. 1981 Am. Mineral. 66

[4] Autefage, F. and Couderc, J.-J. 1980 Bull. Mineralogy 103

[5] Jurek, K et.al. 1996 Mikrochim. Acta (Supp) 13 


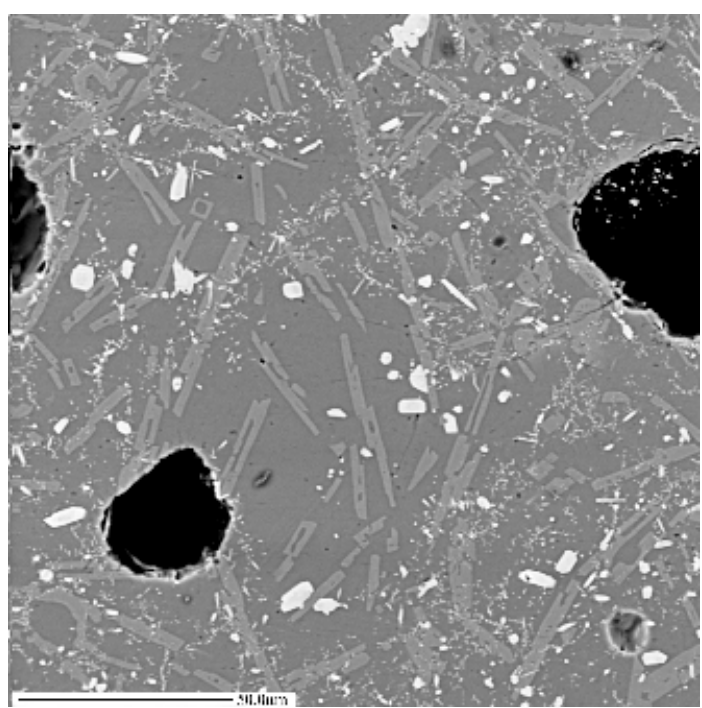

Figure 1 Backscatter electron image of andesite from 1997 Montserrat eruption

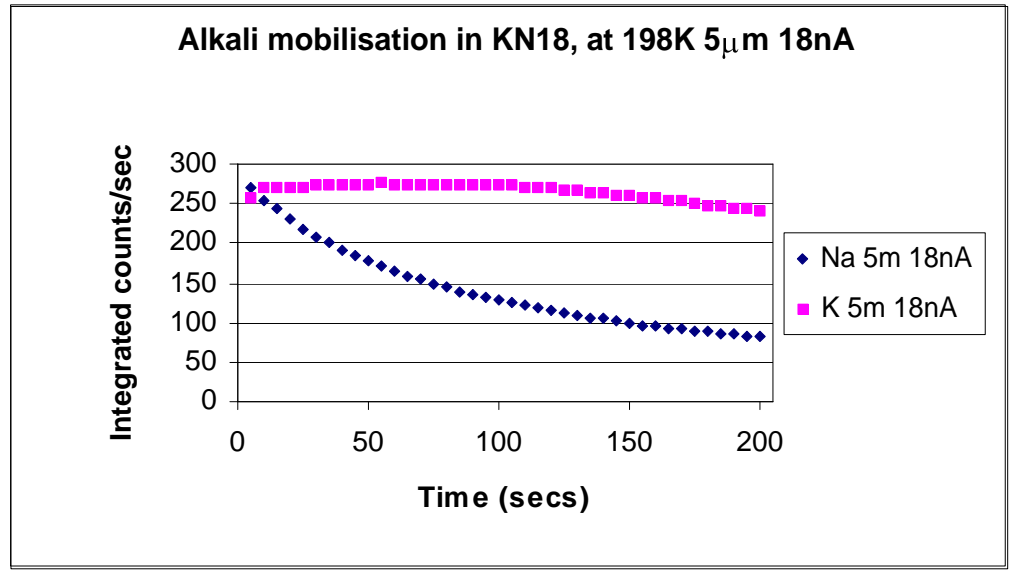

Figure 2 Decay Curve in KN18 glass at ambient temperature

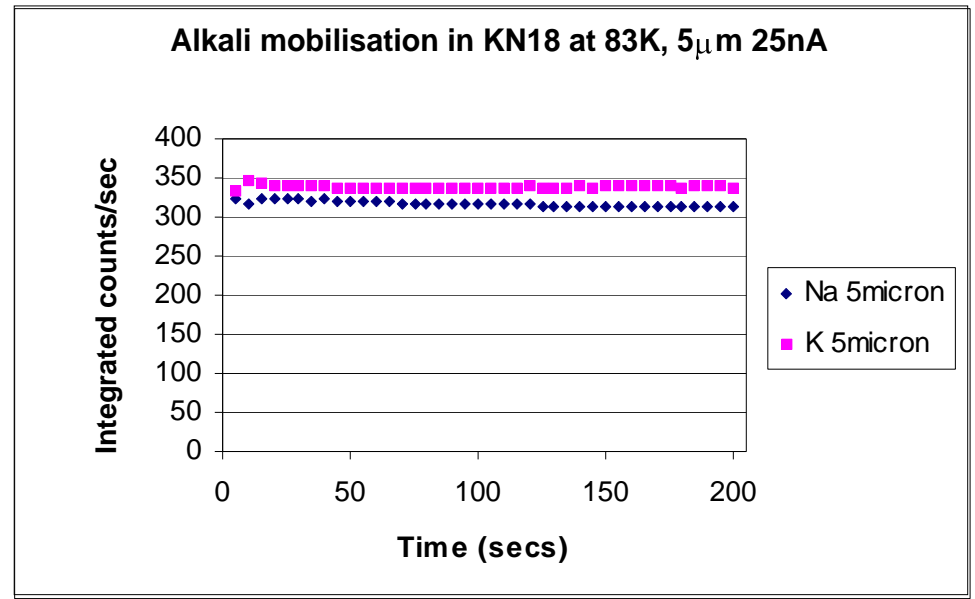

Figure 3 Decay Curve in KN18 glass at cryogenic temperture 